\title{
KERELASIAN, KOMUNIKASI, DAN LINGKUNGAN KERJA MENINGKATKAN KEPUASAN KERJA GURU TAMAN KANAK KANAK DI KECAMATAN BUNGBULANG GARUT
}

\author{
Rasmiyatun $^{1}$, Taufik Zulfikar ${ }^{2}$,Agus Mulyanto ${ }^{3}$ \\ 1,2, Universitas Sangga Buana \\ ${ }^{3}$ Universitas Islam Nusantara \\ ${ }^{1}$ korespondensi : nrasmiyatun@gmail.com
}

\begin{abstract}
Satisfaction is an important keyword for every individual in carrying out their activities, including teachers in carrying out their routines at school in the form of teacher job satisfaction. Teacher job satisfaction is a reflection of the attitudes and feelings of a teacher towards his work in teaching and learning activities at school. A teacher's job satisfaction can be caused by work relations, communication, and a good work environment. This study aims to determine and examine the effect of work relations, communication, and work enviroment on teacher job satisfaction with the reasearch subject of Kindergarten teachers in Bungbulang Garut District . Quantitative is a research method used with a descriptive verification approach. This study uses multiple linear regression analysis tools. A sample of 81 people was obtained from the population using the Slovin method with 0.05 standard error. The data was obtained by distributing questionnaires with 31 questions, random sampling was used to determine the data. The results show descriptively that job satisfaction is perceived to be the smallest variable on average with good categories. Verificative results show that relationships, communication, and work environment have partial or simultaneous effect on job satisfaction.
\end{abstract}

Keywords: Relationship, Communication, Work Environment, Job Satisfaction

\begin{abstract}
ABSTRAK
Bagi setiap individu dalam menjalankan aktifiktasnya, kepuasan menjadi kata kunci penting, termasuk guru dalam menjalani aktifitas rutinnya di sekolah berupa kepuasan kerja guru. Cerminan sikap dan perasaan seorang guru terhadap pekerjaannya tercermin dari kepuasan kerja dalam kegiatan belajar mengajar di sesolah. Kepuasan kerja seorang guru dapat disebabkan oleh kerelasian kerja, komunikasi, dan lingkungan kerja yang baik. Penelitian ini bertujuan untuk mengetahui dan mengkaji pengaruh kerelasian kerja, komunikasi, dan lingkungan kerja terhadap kepuasan kerja guru dengan subjek penelitian guru TK di Kecamatan Bungbulang Garut. Kuntitatif adalah metode penelitian yang digunakan dengan pendekatan deskriptif verifikatif. Penelitian ini mempergunakan alat analisis regresi linear berganda. Sample sebanyak 81 orang diperoleh dari populasi dengan menggunakan metode slovin dengan 0,05 standard error. Data diperoleh dengan menyebarkan kuesioner dengan 31 butir pertanyaan, random sampling digunakan sebagai penentuan data. Hasil menunjukkan secara deskriptif bahwa kepuasan kerja dipersepsikan menjadi variabel terkecil rata-rata dengan kategori baik. Hasil secara verifikatif menunjukkan bahwa kerelasian, komunikasi, dan lingkungan kerja berpengaruh secara parsial maupun simultan terhadap kepuasan kerja.
\end{abstract}

Kata Kunci : Kerelasian, Komunikasi, Lingkungan Kerja, Kepuasan Kerja

\section{PENDAHULUAN}

Berdasarkan Undang-undang Nomor 20 tahuin 2003 tentang Sistem Pendidikan Nasional Bab 1 dinyatakan bahwa Pendidikan Anak Usia Dini (PAUD) adalah suatu upaya pembinaan yang ditujukan kepada anak sejak lahir sampai dengan usia enam tahun yang dilakukan melalui pemberian rangsangan pendidikan untuk membentuk pertumbuhan dan perkembangan jasmani dan rohani agar anak memiliki kesiapan dalam memasuki pendidikan lebih lanjut. Penyelenggaraan pendidikan anak usia dini dapat dilakukan dalam bentuk formal dan non formal. Setiap bentuk penyelenggaraan memiliki kekhasan tersendiri. Penyelenggaraan pendidikan anak 
usia dini pada jalur formal adalah Taman Kanak-kanak (TK) atau RA dan lembaga sejenis. Penyelenggaraan pendidikan bagi anak usia dini jalur non formal diselenggarakan oleh masyarakat atas dasar dari kebutuhan masyarakat sendiri, khususnya bagi anak-anak yang dengan keterbatasan tidak terlayani di pendidikan formal yaitu TK dan RA. Satuan pendidikan anak usia dini merupakan institusi pendidikan anak usia dini yang memberikan layanan pendidikan bagi anak usia baru lahir sampai dengan enam tahun. Di Indonesia ada beberapa lembaga pedidikan anak usia dini yang selama ini sudah dikenal oleh masyarakat luas, yaitu : 1) Taman Kanak-kanak (TK) atau Raudhatul Athfal (RA) merupakan bentuk satuan pendidikan bagi anak usia dini pada jalur formal yang menyelenggarakan pendidikan bagi anak usia 4-6 tahun. 2) Kelompok Bermain (Play Group) Kelompok bermain merupakan salah satu bentuk pendidikan anak usia dini pada jalur pendidikan nonformal yang menyelenggaraan program pendidikan sekaligus program kesejahteraan bagi anak usia 2 sampai dengan 4 tahun. 3) Taman Penitipan Anak (TPA) Taman penitipan anak salah satu bentuk pendidikan anak usia dini pada jalur pendidikan nonformal yang menyelenggarakan program pendidikan dan sekaligus pengasuhan dan kesejahteraan anak sejak lahir sampai dengan usia 6 tahun [1]. Pendidikan usia dini di Kecamatan Bungbulang Kabupaten Garut saat ini berkembang dengan pesat dimana dalam satu wilayah kecamatan memiliki 96 (Sembilan puluh enam) penyelenggara pendidikan usia dini. Terdapat sekitar 353 guru dan tendik yang harus membina dan mendidik sebanyak 3.012 peserta didik usia dini [2]. Membina dan memdidik anak pada usia dini bukan suatu pekerjaan mudah, dibutuhkan ketrampilan, motivasi, dan dedikasi dari seorang guru. Guru dengan kinerja baiklah yang akan memciptakan anak didik yang berkarakter dan sukses yang dapat melanjutkan ke jenjang pendidikan yang lebih tinggi dengan dilandasi kemampuan akademik memadai. Sumber Daya Manusia adalah salah satu kunci sukses dunia pendidikan dari pendidikan usia dini sampai pendidikan tinggi. Sikap dan perasaan seorang guru terhadap pekerjaan dalam kegiatan belajar mengajar di sekolah merupakan cerminan dari kepuasan kerja seorang guru. Adanya rasa bangga dengan hasil pekerjaannya, senang akan pekerjaan, bergairah ketika mengajar, dan melaksanakan pekerjaan dengan penuh tanggung jawab tanda dari sikap dan perilaku guru yang puas dengan pekerjaannya. [3]. Kepuasan kerja guru adalah tercermin dari rasa senang pada seorang guru yang telah melakukan tugasnya dengan sungguh-sungguh yang diwujudkan denganrasa bangga karena tugas tersebut sudah seseuai dengan yang diharapkan serta memberikan umpan balik yang positif kepadanya, itu artinya dalam kepuasan kerja ada kesungguhan dalam menjalankan tugas, ada rasa senang dalam mengerjakan dan ada umpan balik yang sudah tentu memberikan manfaat bagi seorang guru [4]. Peningkatan kinerja dan produktifitas baik untuk karyawan maupun organisasi dapat dilakukan dengan mengelola sumber daya manusia dengan 
efektif dan efisien. Oleh karena itu, penting bagi organisasi untuk memperhatikan faktorfaktor yang dapat mempengaruhi kinerja dan produktifitas yang salah satu faktor tersebut adalah kepuasan kerja [5]. Kepuasan kerja memberikan kontribusi terhadap peningkatan produktivitas kerja menuju pencapaian tujuan organisasi [6]. Judge et al dan Ostroff mengatakan kepuasan kerja merupakan elemen penting yang berkorelasi signifikan dengan perkembangan organisasi, di mana itu mengukur sentimen seorang karyawan untuk pekerjaan yang mereka lakukan [6] . Robbins menyatakan mengenai efek kepuasan kerja pada kinerja pegawai. Pegawai yang puas mempunyai kemungkinan yang lebih besar untuk mendiskusikan hal-hal positif tentang organisasinya, membantu orang lain, dan berkinerja melampaui perkiraan normal [7].

Kinerja guru dapat dipengaruhi oleh salah satu faktor eksternal yaitu peran kepala sekolah. Kepala sekolah mempunyai peran yang strategis dalam menciptakan guru yang professional sebab guru yang professional memerlukan pemimpin dan kepemimpinan kepala sekolah yang professional. Sebagai seorang supervisor, kerelasian antara kepala sekolah dengan guru merupakan faktor yang penting, kepala sekolah diharapkan mampu meningkatkan keterlibatan guru secara individu delam rangka meningkatkan kualitas sekolah yang bermutu, memadukan informasi yang ada di lingkungan sekolah, staretgi pencapaian tujuan manajemen pendidikan yang diterapkan, cara dan sistem kerja, serta kinerja, dengan cara yang proposional, menyeluruh dan berkelanjutan dan mengaktualkan kemampuan professional guru [8], George \& Jones juga menganjurkan bahwa kerelasian pegawai melibatkan komunikasi dan hubungan antara manajemen dan pegawainya yang bertujuan untuk mempertahankan hubungan antara pemberi kerja-pegawai yang pada akhirnya memberikan kontribusi yang memuaskan terhadap produktivitas, kepuasan kerja, motivasi, dan semangat kerja para pegawai [9]. Hubungan manajemen-pegawai yang baik diperlukan untuk organisasi yang memuaskan dan kinerja perusahaan mana pun dan agar karyawan merasa terlibat [10]. Praktik SDM yang baik saja tidak cukup. Apa yang membuat perbedaan yang lebih besar adalah cara orang bekerja sama untuk menjadi produktif dan cukup fleksibel untuk menghadapi tantangan baru' Ini difasilitasi oleh dua bahan utama a) pendekatan manajemen sumber daya manusia diambil oleh manajer lini dan b) budaya organisasi positif yang didukung oleh kepemimpinan berbasis nilai yang kuat dari manager senior. Pada institusi pendidikan atau sekolah, untuk melaksanakan fungsinya dengan baik diperlukan kerja sama diantara semua unsur, sebab kerja tim akan dapat dapat meningkatkan kepercayaan diri, komunikasi, dan mengembangkan kemandirian. Semua permasalahan, program, dan kebijakan sekolah harus dikomunikasikan dengan baik agar semua warga sekolah mengetahui dan tidak ada perbedaan persepsi satu sama lain. Pentingnya komunikasi dalam suatu tim adalah untuk memelihara sifat-sifat yang baik dan bermanfaat, dan dasar komunikasi yang 
antar anggota adalah kejujuran dan integritas [11]. Komunikasi adalah salah satu faktor terpenting dalam fungsi organisasi dan hal itu diketahui karyawan mencurahkan sebagian besar hari kerja mereka untuk mengumpulkan dan menyebarkan informasi mengenai hal-hal penting seperti kebijakan organisasi, umpan balik kinerja, ekspektasi peran, dan instruksi tugas [12]. Peran komunikasi di tempat kerja merupakan elemen penting dalam memastikan kinerja untuk mencapai tujuan organisasi [6]. Komunikasi terbuka dalam organisasi mengarah pada peningkatan kepuasan dengan keterlibatan karyawan [13]. Komunikasi organisasi sangat penting untuk terlibat dengan hubungan lebih baik dalam suatu organisasi, untuk mengirimkan informasi, memiliki kepercayaan dan bekerja sama dengan masing-masing lainnya, untuk memahami dan mengkoordinasikan pekerjaan, untuk meningkatkan iklim komunikasi dan pembelajaran, dan karenanya untuk meningkatkan kepuasan tempat kerja secara keseluruhan dan juga kepuasan kerja individu [14]. Proses komunikasi di dalam sekolah sebagai institusi yang menyelenggarakan pendidikan adalah komunikasi internal, yang arah komunikasinya dapat bersifat: a) vertical (dari atas ke bawah atau dari bawah ke atas), yaitu komunikasi antara kepala sekolah dengan guru atau kepala sekolah dengan staf tata usaha; b) horizontal, yaitu komunikasi antara guru dengan guru; guru dengan guru; dan c) diagonal, yaitu komunikasi antara guru dengan staf tata usaha [11].
Guru sebagai tenaga profesional di bidang pendidikan, di samping memahami hal-hal yang bersifat filosofis dan konseptual, juga harus mengetahui dan melaksankan hal-hal yang bersifat teknis. Hal-hal yang bersifat teknis ini, terutama kegiatan mengelola dan melaksanakan interaksi belajar mengajar. Di dalam mengelola kegiatan interaksi belajar mengajar, guru paling tidak harus memiliki dua modal dasar, yakni kemampuan mendesain program dan keterampilan mengomunikasikan program kepada siswa. Salah satu komunikasi yang terjadi adalah komunikasi interpersonal guru dan siswa [15]. Didalam komunikasi antarpribadi guru dan siswa sangat diperlukan adanya sikap keterbukaan satu sama lain, empati, berpikir positif, dukungan dan kesetaraan diantara keduanya, dan komunikasi yang seperti itulah yang dapat meminimalisir kesenjangan diantara guru dan siswa, meminimalisir saling tidak percaya dan meningkatkan rasa ingin tau siswa dan termotivasi dalam belajar.2 Namun dalam kenyataannya tidak semua guru mampu untuk berkomunikasi yang baik dan efektif yang diharapkan dapat mengubah sikap dan tingkah laku siswa agar giat dan termotivasi dalam belajar [16].

Faktor lain yang dapat mempengaruhi kepuasan kerja seoarng guru dalam menjalankan tugas adalah lingkungan kerja yaitu segala sesuatu yang ada di sekitar guru, yang dapat mempengaruhi dirinya dalam melaksanakan tugas. Lingkungan kerja yang nyaman dan aman akan membuat guru juga ikut merasa nyaman dalam bekerja sehingga tugas yang dikerjakan oleh para gura juga 
dapat dilakukan dengan baik dan itu mempengaruhi kepuasan kerja guru [17]. Kenyaman bagi guru dapat diberikan dengan tersedianya lingkungan kerja yang baik. Di dalam melakukan kegiatan belajar dan mengajar guru harus dapat merasakan kenyamanan dalam bekerja, sehingga dapat berkonsenrasi penuh dalam memberikan dan menyampaikan pengetahuan kepada siswa, karena peran guru sebagai tenaga pengajar yang berhubungan dan bertatap muka memberikan pengaruh yang kuat kepada para siswa [18]. Ketidak puasan kerja seseorang, selain prestasi kerja, tingkat keinginan pindah kerja, usia pekerjaan, tingkat jabatan, dan besarnya kecilnya institusi/organisasi dipengaruhi oleh situasi lingkungan kerja. (Siagian dalam [19]. Berdasarkan fenomena tersebut di atas maka penelitian ini bertujuan untuk mengkaji hubungan antara kerelasian, komunikasi, lingkungan kerja, dan kepuasan kerja guru taman kanak-kanak di Kecamatan Bungbulang Kabupaten Garut.

\section{TINJAUAN PUSTAKA}

\section{Kerelasian}

Jackson dan Schuler mendefinisikan manajemen hubungan karyawan sebagai suatu sistem yang menarik, mengembangkan, memotivasi, dan mempertahankan pekerja sehingga menjadi anggotanya dan organisasi diterapkan secara efektif dan dijamin kelangsungan hidupnya [20]. Wang menyesebutkan bahwa praktik manajemen hubungan karyawan dianggap inovatif perusahaan sebagai strategi organisasi untuk mendorong tanggung jawab tim, peningkatan budaya organisasi dan membangun hubungan pelanggan melalui pemberdayaan dan partisipasi [20]. Manajemen kerelasian pegawai adalah proses yang digunakan organisasi untuk secara efektif mengelola semua interaksi dengan pegawai, pada akhirnya untuk mencapai tujuan organisasi [9]. hubungan positif antara dua atau lebih banyak orang yang terlibat dalam hubungan sosial dan otoritatif dalam sebuah organisasi [21].

\section{Dimensi Kerelasian}

Dimensi dari kerelasian pegawai adalah lingkungan kerja, penghargaan, support, keadilan, hubungan dengan atasan, kepuasan diri dan pembelajaran [22]. Penerapan manajemen kerelasian pegawai adalah :a. Dicipline procedures : Peraturan, Tata Tertib, Tata Cara, Hukum, Agama, dan Konstitusi mendefinisikan kerangka kerja untuk melaksanakan tugas rutin dalam kehidupan pribadi dan profesional dalam sebuah lingkaran kehidupan. b. Conflict management : sebuah organisasi untuk tumbuh secara efektif dan efisien itu tergantung pada cara mengelola konflik di dalamnya organisasi.c. Trade unionism : Serikat pekerja bertindak sebagai jembatan komunikasi antara pengusaha dan karyawan selama pengaduan dan perjanjian kerja bersama. $d$. Communication : Komunikasi memainkan peran penting dalam organisasi dan merupakan salah satu faktor terpenting yang meningkatkan hubungan antar karyawan [20]. Ketika komunikasi terbuka dan transparan, karyawan dapat membangun kepercayaan 
yang tinggi organisasi mereka dan menganggap organisasi tersebut transparan. d. Grievance management : Bagaimana manajemen menguraikan masalah yang muncul diantara karyawan.

Menurut Schweitzer \& Lyons praktik manajemen kerelasian meliputi: Pemberdayaan dan keterlibatan karyawan, memprakarsai saran karyawan, memfasilitasi perundingan bersama, manajemen konflik dan langkah-langkah penanganan keluhan, pelatihan dan pengembangan keahlian, transparansi dalam komunikasi,dan mendorong kegiatan kelompok (teamwork) [9].

\section{Komunikasi}

Komunikasi berasal dari bahasa Latin communis, yang berarti 'membuat kebersamaan' atau 'membangun kebersamaan antara dua orang atau lebih'. Akar kata communis adalah communico, yang artinya 'berbagi'. Dalam hal ini, yang dibagi adalah pemahaman bersama melalui pertukaran pesan . Komunikasi sebagai kata kerja (verb) dalam bahasa Inggris, communicate, berarti: Untuk bertukar pikiran-pikiran, perasaanperasaan, untuk menjadikan paham (tahu), untuk membuat sama, dan, untuk mempunyai sebuah hubungan yang simpatik. Komunikasi dapat didefinisikan sebagai usaha penyampaian pesan antar manusia [23]. Hidayat [24] menyatakan bahwa komunikasi adalah usaha untuk membangun sebuah kebersamaan yang dilandasi oleh persamaan persepsi tentang sesuatu sehingga mendorong diantara pelaku komunikasi untuk saling memahami sesuai dengan keinginan atau tujua bersama [24]. Sedangkan menurut Djamarah komunikasi dapat didefinisikan sebagai suatu proses pertukaran informasi yang dilakukan oleh dua orang atau lebih yang akan saling memberikan pengertian yang mendalam [24]. Menurut Komala komunikasi adalah suatu proses pertukaran informasi yang dilakukan oleh dua orang atau lebih yang akan saling memberikan pengertian yang mendalam.Komunikasi diartikan sebagai proses pertukaran informasi melalui individu melalui simbol-simbol seperti tanda, tingkah laku, olah raga, dan begitu seterusnya [24]. Komunikasi di tempat kerja dapat terjadi dalam berbagai bentuk komunikasi verbal dan nonverbal. Komunikasi verbal diartikan sebagai komunikasi tatap muka dengan menggunakan mulut (lisan) dalam penyampaian informasi ketika berbicara dengan rekan kerja seperti tatap muka, rapat, dan percakapan melalui telepon. Komunikasi non-verbal adalah pesan yang disampaikan tanpa penggunaan kata-kata seperti gerak dan cara berdiri atau duduk, wajah dan mata gerakan, sinyal suara dan, menggunakan banyak tubuh atau jarak [6].

\section{Dimensi Komunikasi}

Dimensi komunikasi internal adalah : a. Komunikasi internal ke bawah, b.Komunikasi internal ke atas, c.Komunikasi internal horizontal, d.Komunikasi internal diagonal. Proses komuniaksi di dalam sekolah sebagai institusi yang menyelenggarakan pendidikan adalah komunikasi internal, yang arah komunikasinya dapat bersifat: Vertikal (dari 
atas ke bawah atau dari bawah ke atas), yaitu komunikasi antara kepala sekolah dengan guru atau kepala sekolah dengan staf, Horisontal, yaitu komunikasi antara guru dengan guru, dan Diagonal, yaitu komunikasi antara guru dengan staf tata uaha [11].

Devito menyatakan bahwa komunikasi interpersonal adalah penyampaian pesan oleh satu orang dan penerimaan pesan oleh orang lain atau sekelompok kecil orang, dengan berbagai dampaknya dan dengan peluang memberikan umpan balik segera. Proses komunikasi interpersonal tersebut, akan lebih mendekatkan hubungan antara guru dan siswa [15]. Hal itu di dukung oleh Cangara yang mengatakan bahwa fungsi komunikasi antar pribadi adalah berusaha meningkatkan hubungan insani (human relations), menghindari konflik, dan mengatasi konflik pribadi, mengurangi ketidakpastian sesuatu, serta berbagi pengetahuan dan pengalaman dengan orang lain [15]. Sedangkan menurut Wiryanto [25]) Komuniaksi antar pribadi merupakan komunikasi yang berlangsung dalam situasi tatap muka antara dua orang atau lebih, baik secara terorganisasi maupun pada kerumuman orang [25]. Dimensi dari komunikasi antar pribadi menurut yaitu : Keterbukaan, Empati, Sikap mendukung, Sikap positif, Kesetaraan [25]. Secara bentuk menurut Mulayana dalam terdapat dua bentuk komunikasi yaitu komunikasi verbal adan non verbal [25]. Komunikasi verbal adalah komunikasi yang berdasarkan pada interaksi antar manusia dengan mempergunakan katakata lisan maupun tulisan serta dilakuka secara sadar berhubungan dengan manusia lain. Sementara menurut Vardeber berpendapat bahwa komunikasi verbal Komunikasi verbal dapat dilakukan secara lisan maupun tuliasan dengan menggunakan bahasa sebagai alat komunikasi. Jadi komunikasi yang dilakukan menggunakan symbol yang telah disepakati dalam suatu bahasa [25].

\section{Lingkungan Kerja}

Seperangkat atribut yang memberi warna atau karakter, spirit, etos, suasana batin dari setiap sekolah merupakan iklim lingkungan kerja di sekolah yang didefinisikan oleh (Fisher and Fraser, [18]. Lingkungan kerja merupakan tempat dimana guru melakukan aktivitas setiap harinya. Lingkungan kerja yang kondusif memberikan rasa nyaman dan aman serta memungkinkan guru dapat bekerja optimal [11]), Menurut Nitisemito mengartikan lingkungan kerja sebagai segala sesuatu yang ada di sekitar guru yang dapat mempengaruhi dirinya dalam melaksanakan tugas-tugas yang diberikan [11]. Menurut Schultz dalam mendefinisikan bahwa lingkungan kerja atau kondisi kerja adalah semua elemen fisik kerja, psikologi kerja dan peraturan kerja yang dapat mempengaruhi kepuasan kerja dan produktifitas kerja [11]

\section{Dimensi Lingkungan Kerja}

Menurut Teguh Sulistitiyani dan Rosidah maksud dari faktor lingkungan kerja antara lain ; kesehatan, jaminan kemanan, pelayanan, pola komunikasi, dan fasilitas kerja. Adapun uraian dari masing-masing faktor lingkungan kerja adalah sebagai berikut : a. Kesehatan. b. 
Jaminan keamanan pegawai,. c. Pelayanan [19]. Faktor- faktor yang dapat mempengaruhi lingkungan kerja fisik yang dikemukakan oleh Sedarmayanti antara lain: Pencahayaan, suhu, kelembaban, sirkulasi udara, tingkat kebisingan, getaran mekanis, aroma, tata warna, dekorasi, alunan musik serta keamanan di tempat kerja [17]. Adapun indikator lingkungan kerja non fisik menurut pendapat Soetjipto diantaranya : Hubungan yang harmonis, kesempatan untuk maju, kemanan dan kenyaman dalam pekerjaan [17].

\section{Kepuasan Kerja}

Kepuasan Kerja didefinisikan sebagai keadaan emosi yang tidak menyenangkan yang dihasilkan dari penilaian pekerjaan yang dilakukan. Ini juga mempengaruhi sikap dan respon itu efektif terhadap pekerjaan seseorang. Apalagi sikap akan mempengaruhi kepuasan kerja tetapi juga harus dibedakan melalui evaluasi kognitif yang memengaruhi emosi, keyakinan, dan perilaku [6]. Robbins dan Judge berpendapat bahwa kepuasan kerja adalah suatu perasaan positif tentang pekerjaan, yang dihasilkan dari suatu evaluasi pada kerakteristik-karakteristiknya [5]. Seseorang dengan tingkat kepuasan kerja yang tinggi memiliki perasaan positif mengenai pekerjaannya, sedangkan seseorang dengan tingkat kepuasan kerja rendah memiliki perasaan negative mengenai pekerjaannya. Kepuasan kerja merupakan sikap pribadi terhadap pekerjaan dan sikap yang positif situasi emosional ketika karyawan mencapai harapan mereka atas pekerjaan dan karier mereka [12]. Luthan mendefinisikan kepuasan kerja adalah hasil dari persepsi karyawan tentang seberapa baik hasil pekerjaannya segala sesuatu yang dipandang penting melalui karyanya [26]. Menurut Herzberg terdapat dua jenis faktor yang mendorong seseorang untuk berusaha mencapai kepuasan kerja dan menjauhkan diri dari ketidak puasan kerja. Dua faktor itu disebutnya faktor hygiene (faktor luar/ekstrinsik) dan faktor motivator (faktor dalam/intrinsik) Faktor hygiene memotivasi seseorang untuk keluar dari ketidak puasan, Faktor eketernal tersebut termasuk gaju, keamanan kerja, kondisi kerja, pengawasan, hubungan inter personel, kebijakan, dan administrasi. Faktor motivator memotivasi seseorang untuk berusaha mencapai kepuasan, yang termasuk didalamnya adalah pencapaian atau penyelesaian pada suatu pekerjaan, pengenalan untuk menyelesaikan pekerjaan dan tugas itu sendiri, kelanjuatan dan pertumbuhan dalam kemampuan pekerjaan [27].

\section{Dimensi Kepuasan Kerja}

Spector mengemukakan bahwa kepuasan kerja secara global dapat diperoleh dengan menjumlahkan keseluruhan tingkat kepuasan terhadap aspek-aspek dalam pekerjaan [28]. Aspek penentu kepuasan kerja, yaitu: Gaji, Promosi, Supervisi, Benefit, Pengakuan, Prosedur dan peraturan kerja, Rekan kerja, Jenis pekerjaan, Komunikasi. Faktor-faktor yang mempengaruhi kepuasan kerja adalah : Isi pekerjaan, Manajemen, Lingkungan kerja, Kompensasi, Promosi kerja, Pelatihan kerja [5] 
Hubungan Kerelasian dengan Kepuasan Kerja

Penelitian yang dilakukan oleh BulinskaStangrecka, H.; Baginska, A (2021) dengan judul The Role of Employee Relations in Shaping Job Satisfaction as an Element Promoting Positive Mental Health at Work in the Era of COVID-19. Dimuat pada International Journal. Environmental Research and Public Health, Vol 18, Issue 4, pp 1-19, menemukan adanya pengaruh positif antara kerelasian terhadap kepuasan kerja. Penelitian yang dilakukan oleh Mishra dan Dimri (2017) dengan judul Analysis of employee relationship management pada Journal of Arts, Science \& Commerce Vol. 2, Issue 10 pp 15-25 menunjukan bahwa ada hubungan positif antara penerapan semua kerelasian manajemen terhadap kepuasan kerja.

Hipotesis 1 : Terdapat pengaruh kerelasian terhadap kepuasan kerja

\section{Hubungan Komunikasi dengan Kepuasan Kerja}

Chitrao dengan judul penelitian Communication and Job Satisfaction among Workers in the Department of Trade Union Affairs in the Northern State of Malaysia menjelaskan bahwa komunikasi yang positif dan baik dapat meningkatkan kepuasan kerja dan mengurangi keluhan pada pegawai yang bekerja terbit pada jurnal European Scientific Journal ESJ Vol. 15, Issue 28 [6]. Penelitian yang dilakukan oleh Kulachai (2018) dengan penelitian yang berjudul Internal communication, employee participation, job satisfaction, and employee performance menemukan bahwa terdapat hubungan positif antara internal dan kepuasan kerja pegawai terbit pada jurnal Advances in Social Science, Education and Humanities Research (ASSEHR), Vol 186, pp 124-128 [29]. Penelitian yang dilakukan oleh Ali dan Haider (2012) dalam jurnalnya yang berjudul Impact of internal organizational communications on employee job satisfaction- Case of some Pakistani yang menyatakan untuk tujuan ini, kami mengajukan tiga pertanyaan dan mengembangkan tiga hipotesis untuk menemukan dampak dari tiga dimensi dasar organisasi internal komunikasi tentang kepuasan kerja. Tiga dasar dimensi organisasi adalah iklim komunikasi yang berdampak positif pada pekerjaan karyawan kepuasan. Hal penting berikutnya untuk sebuah organisasi adalah komunikasi formal yang berdampak positif pada kepuasan kerja karyawan. Hal ketiga dan terakhir itu yang telah kami bahas dalam penelitian kami adalah Informal komunikasi yang berdampak positif bagi kepuasan kerja karyawan terbit pada jurnal Global Advanced Research Journal of Management and Business Studies Vol. 1 Issue 10, pp 38-44 [14]

Hipotesis 2 : Terdapat pengaruh komunikasi terhadap kepuasan kerja.

Hubungan Lingkungan Kerja dengan Kepuasan Kerja

Penelitian yang dilakukan oleh Mhd. Andi Rasyid dan Hasrudy Tanjung dengan judul 
Pengaruh Kompensasi, Lingkungan Kerja dan Motivasi Terhadap Kepuasan Kerja Guru pada SMA Swasta Perkumpulan Amal Bakti 4 Sampali Medan terbit pada Maneggio: Jurnal Ilmiah Magister Manajemen Vol. 3, No. 1 Tahun 2020 dengan hasil penelitian menemukan bahwa kompensasi memiliki pengaruh yang signifikan terhadap kepuasan kerja secara parsial. Kompensasi, lingkungan kerja, dan motivasi meiliki pengaruh yang signfikan terhadap kepuasan kerja secara simultan. Penelitian yang dilakukan oleh Sentot Iskandar dan Enceng Juhana dengan judul penelitian Pengaruh Kompetensi dan Lingkungan Kerja terhadap Kepuasan Kerja serta Implikasinya Pada Kinerja Guru di SDN Baros Mandiri 5 Kota Cimahi yang terbit pada Jurnal Ekonomi, Bisnis dan Entrepreneurship Vol. 8, No. 2 Tahun 2014 menunjukan hasil bahwa kesimpulannya terbukti ada pengaruh secara signifikan antara kompetensi, lingkungan kerja terhadap kepuasan kerja serta implikasinya terhadap kinerja guru. Penelitian yang dilakukan oleh Fajar Maya Sari dengan judul penelitian Pengaruh Kompetensi Dan Lingkungan Kerja Terhadap Kepuasan Kerja Dan Kinerja Guru Di Sd Negeri Kecamatan Gondang Mojokerto terbit pada jurnal DIE, Jurnal Ilmu Ekonomi dan Manajemen Vol. 9 No. 2 Tahun 2013 dengan hasil penelitian hasil penelitian menunjukkan bahwa : (1) Kompetensi dan lingkungan kerja berpengaruh signifikan terhadap kepuasan kerja guru, (2) Kompetensi dan lingkungan kerja dilakukan tidak memiliki pengaruh yang signifikan terhadap kinerja guru (3) Kepuasan kerja berpengaruh signifikan terhadap kinerja
guruHipotesis 3 : Terdapat pengaruh lingkungan kerja terhadap kepuasan kerja.

Hipotesis 4 : Terdapat pengaruh kerelasian, komunikasi, dan lingkungan kerja terhadap kepuasan kerja secara simultan.

\section{METODE}

Metode kuantitatif digunakan dalam penelitian ini dengan pendekatan deskriptif dan verifikatif. Data diperoleh dengan menyebarkan kuesioner kepada responden sebanyak 81 orang guru taman kanak-kanak yang berada di Kecamatan Bungbulang Garut. Data diperoleh dengan memberikan kuesioner sebanyak 31 pertanyaan tertutup. Metode penentuan sample yaitu sampling random. Alat analisa yang digunakan regresi linear berganda dengan persamaan sebagai berikut :

$Y_{i}=\alpha+\beta_{1} X_{1}+\beta_{2} X_{2}+\beta_{3} X_{3}$

Dimana :

$\mathrm{Y}=$ Variabel Kepuasan Kerja

$\mathrm{a}=$ Konstanta

$\mathrm{b}=$ Koefisien regresi

$\mathrm{X} 1=$ Variabel Kerelasian

$\mathrm{X} 2=$ Variabel Komunikasi

X3 = Variabel Lingkungan Kerja

\section{HASIL DAN PEMBAHASAN}

\section{Data Responden}

Karakteristik responden yang diteliti dikelompokan berdasarkan jenis kelamin, usia, latar belakang pendidikan

Tabel 1 menunjukan bahwa guru taman kanak-kanak didomiansi oleh pria dibanding wanita dengan perbandingan $70: 30$. Rentang usia guru taman kanak-kanak adalah 25 tahun 
sampai dengan 45 tahun sebanyak $2 / 3$ dari seluruh guru taman kanak-kanak. Latar belakang pendidikan guru taman kanak-kanak didominasi oleh guru yang berlatar belakang pendidikan SMA dan Sarjana.

Tabel 1 : Responden

\begin{tabular}{llrr}
\hline Keterangan & Kategori & Frekuensi & Persen \\
\cline { 2 - 5 } Jenis Kelamin & Pria & 24 & 30 \\
& Wanita & 57 & 70 \\
\hline Usia & $<25$ tahun & 3 & 4 \\
& $25,1-35$ tahun & 30 & 36 \\
& $35,1-45$ tahun & 25 & 31 \\
& $>45$ tahun & 23 & 29 \\
\hline Pendidikan & SMA & 38 & 47 \\
& Diploma & 2 & 2 \\
& Sarjana & 40 & 50 \\
& Pascasarjana & 1 & 1 \\
\hline
\end{tabular}

Sumber : Data primer yang diolah

\section{Hasil Uji Validitas dan Uji Reliabilitas}

Variabel

Kerelasian,

Komunikasi,

Lingkungan Kerja dan Kepuasan Kerja berdasarkan output IBM SPSS 20.0 yang telah direkapitulasi menunjukan bahwa nilai koefisien validitas untuk tiap-tiap variabel menunjukan angka di atas $r$ tabel 0,3 maka pertanyaan-pertanyaan tersebut diputuskan signifikan dan memiliki validitas yang baik. Nilai Cronbach Alpha variabel Kerelasian sebesar 0,776. Variabel Komunikasi sebesar 0,870. variabel Lingkungan kerja sebesar 0,871. variabel Kepuasan Kerja sebesar 0,869 dimana nilai Crobach Alpha keseluruhan berada di atas 0,6 ini berarti instrument memiliki hasil yang reliabel, sehingga instrument atau angket ini termasuk kepada instrumen reliabel dan konsisten.

\section{Gambaran Persepsi Responden}

Variabel Kerelasian (X1), diwakili oleh 7 (tujuh) item pernyataan skor total 2422 dengan rata-rata 4.27, dapat disimpulkan bahwa persepsi responden berada pada kategori sangat baik. Variabel Komunikasi (X2), diwakili oleh 8 (delapan) item pernyataan skor total 22671 dengan rata-rata 4.12. dapat disimpulkan bahwa persepsi responden berada pada kategori baik. Variabel Lingkungan Kerja (X3), diwakili oleh 9 (sembilan) item pernyataan skor total 2960 dengan rata-rata 4,06. dapat disimpulkan bahwa persepsi responden berada pada kategori baik. Variabel Kepuasan Kerja (Y), diwakili oleh (tujuh) item pernyataan skor total 2156 dengan rata-rata 3,80. dapat disimpulkan bahwa persepsi responden berada pada kategori baik.

\section{Hasil Persamaan Linear Berganda}

Diperoleh bentuk persamaan regresi linier berganda sebagai berikut :

$Y=-0,244+0.395 X_{1}+0.482 X_{2}+0.177 X_{3}$

Dari persamaan regresi linier berganda diatas diperoleh nilai konstanta koefisien Kepuasan 
Kerja sebesar -0.244 memiliki arti ketika Kepuasan Kerja tidak dipengaruhi oleh ketiga variabel bebasnya maka akan bernilai -0.244 . Koefisien regresi untuk variabel bebas $\mathrm{X}_{1}, \mathrm{X}_{2}$, $\mathrm{X}_{3}$ bernilai positif, menunjukkan adanya hubungan yang searah antara variabel bebas terhadap variabel terikat. Koefisien regresi variabel $\mathrm{X}_{1}$ sebesar 0.395 mengandung arti untuk setiap peningkatan $\left(\mathrm{X}_{1}\right)$ sebesar satu satuan akan menyebabkan meningkatnya (Y) sebesar 0.395 satuan. Koefisien regresi variabel $\mathrm{X}_{2}$ sebesar 0.482 mengandung arti untuk setiap peningkatan $\left(\mathrm{X}_{2}\right)$ sebesar satu satuan akan menyebabkan meningkatnya (Y) sebesar 0.491 satuan. Koefisien regresi variabel $\mathrm{X}_{3}$ sebesar 0.177 mengandung arti untuk setiap peningkatan $\left(\mathrm{X}_{3}\right)$ sebesar satu satuan akan menyebabkan meningkatnya (Y) sebesar 0.177 satuan.

\section{Uji t}

Tabel 2 : Hasil Uji t

\begin{tabular}{|c|c|c|c|c|c|c|c|}
\hline \multicolumn{8}{|c|}{ Coefficients $^{\mathrm{a}}$} \\
\hline & & Unstandardize & Coefficients & $\begin{array}{l}\text { Standardized } \\
\text { Coefficients }\end{array}$ & & & Correlations \\
\hline \multicolumn{2}{|c|}{ Model } & $\mathrm{B}$ & Std. Error & Beta & $\mathrm{t}$ & Sig. & Zero-order \\
\hline \multirow[t]{4}{*}{1} & (Constant) & -.244 & .176 & & -1.381 & .171 & \\
\hline & Kerelasian & .395 & .086 & .353 & 4.583 & .000 & .798 \\
\hline & Komunikasi & .482 & .082 & .465 & 5.879 & .000 & .836 \\
\hline & Lingkungan Kerja & 177 & .085 & .174 & 2.100 & .039 & .770 \\
\hline
\end{tabular}

a. Dependent Variable: Kepuasan Kerja

Sumber: Hasil Pengolahan Data Primer, 2021

Berdasarkan tabel 2 di atas dapat dilihat bahwa Variabel Kerelasian $\left(\mathrm{X}_{1}\right)$, Komunikasi $\left(\mathrm{X}_{2}\right)$, Lingkungan Kerja $\left(\mathrm{X}_{3}\right)$ memiliki nilai sig lebih kecil dari 0,05. Karena nilai sig $(0,000)<0,05$, maka Ho ditolak. Oleh karena itu dapat disimpulkan bahwa secara parsial terdapat pengaruh signifikan dari Kompetensi, Komunikasi, dan Lingkungan Kerja terhadap Kinerja Guru..

\section{Uji F}

Diperoleh nilai $F$ hitung sebesar 105,571. Karena nilai F hitung $(105,571)>$ F tabel $(2,72)$, maka Ho ditolak. Dengan demikian dapat disimpulkan bahwa secara simultan terdapat pengaruh yang signifikan dari Kerelasian, Komunikasi, dan Lingkungan Kerja terhadap Kepuasan Kerja..

\section{Koefisien Determinasi}

Diketahui bahwa nilai koefisien korelasi simultan adalah sebesar 0.897 kemudian koefisien determinasi $\left(\mathrm{R}^{2}\right)$ diperoleh nilai sebesar 0.804 . Artinya total pengaruh antara variabel-variabel bebas terhadap varaibel terikat sebesar $80,4 \%$ sedangkan sisanya $19,6 \%$ merupkan pengaruh variabel-variabel lain yang tidak peneliti libatkan dalam penelitian ini. 


\section{Pembahasan}

Pengaruh Kerelasian terhadap Kepuasan Kerja

Hasil yang didapatkan diperoleh dari perhitungan sig 0,000 lebih kecil dari 0,05 dan nilai $t_{\text {hitung }}$ lebih besar dari tabel $(4,583>$ 1.997). Pengaruh kerelasian secara partial besarnya adalah 28,2\% terhadap Kepuasan Kerja.

\section{Pengaruh Komunikasi terhadap Kepuasan}

Kerja

Hasil yang didapatkan diperoleh dari perhitungan sig 0,000 lebih kecil dari 0,05 dan nilai $t_{\text {hitung }}$ lebih besar dari $t_{\text {tabel }}(5,879>$ 1.997). Komunikasi memberikan kontribusi pengaruh secara partial terhadap Kepuasan Kerja sebesar 38,9\% , terbesar dibandingkan pengaruh dua variabel bebas lainnya.

\section{Pengaruh Lingkungan Kerja terhadap}

\section{Kepuasan Kerja}

Hasil yang didapatkan yaitu dari perhitungan sig 0,000 lebih kecil dari 0,05 dan nilai thitung lebih besar dari $t_{\text {tabel }}(2,100>1.997)$. Lingkungan Kerja memberikan kontribusi pengaruh secara partial terhadap Kepuasan Kerja sebesar 13,4\% merupakan kontribusi terkecil dibandingkan dengan dua variabel bebas lainnya.

\section{KESIMPULAN}

1a. Persepsi mengenai Kerelasian Guru TK di Kecamatan Bungbulang Garut berada pada kategori sangat baik. Persepsi terendah yaitu para guru belum diberikan kesempatan untuk menangani keluahan, b. Persepsi mengenai Komunikasi Guru TK di Kecamatan Bungbulang Garut berada pada kategori baik. Persepsi terendah yaitu para guru mengalami hambatan dalam berkomunikasi dengan orang tua peserta didik. c. Persepsi mengenai Lingkungan Kerja Guru TK di Kecamatan Bungbulang Garut berada pada kategori baik. Persepsi terendah yaitu para guru merasakan bahwa ruang kerja atau tempat belajar tidak luas. d. Persepsi mengenai Kepuasan Kerja Guru TK di Kecamatan Bungbulan berada pada kategori baik. Persepsi terendah yaitu para guru belum puas atas pendapatan bersifat non finansial. 2. Besar pengaruh Kerelasian terhadap Kepuasan kerja Guru TK di Kecamatan Bungbulang Kabupaten Garut adalah sebesar 28.2\%. 3.Besar pengaruh Komunikasi terhadap Kepuasan kerja Guru TK di Kecamatan Bungbulang Kabupaten Garut adalah sebesar $38.9 \%$., 4. Besar pengaruh Lingkungan kerja terhadap Kepuasan kerja Guru TK di Kecamatan Bungbulang Kabupaten Garut adalah sebesar 13.4\%., 5. Besar pengaruh Kerelasian, Komunikasi dan Lingkungan kerja terhadap Kepuasan kerja Guru TK di Kecamatan Bungbulang Kabupaten Garut secara simultan adalah sebesar $80.4 \%$.

\section{DAFTAR PUSTAKA}

[1] P. Ayu Yuliantini, I. B. Putra Astika, and D. N. Badera, "Pengaruh Kompetensi Sumber Daya Manusia, Motivasi dan Lingkungan Kerja pada Komitmen Organisasi dan 
Implikasinya pada Kinerja Pengurus Barang Pemerintah Kabupaten Tabanan," E-Jurnal Ekon. dan Bisnis Univ. Udayana, vol. 10, p. 3697, 2017 , doi: 10.24843/eeb.2017.v06.i10.p10.

BPS Kabupaten Garut, "Kabupaten Garut Dalam Angka 2020," Kabupaten Garut dalam Angka 2020, p. 221, 2020, [Online]. Available: https://garutkab.bps.go.id/publication /download.html?nrbvfeve=NzBkZjQ 0Njk1NTk2OWY1ZDMxZjJlMmMy \&xzmn=aHR0cHM6Ly9nYXJ1dGth Yi5icHMuZ28uaWQvcHVibGljYXR pb24vMjAyMC8wNC8yNy83MGR mNDQ2OTU1OTY5ZjVkMzFmMm UyYzIva2FidXBhdGVuLWdhenV0 LWRhbGFtLWFuZ2thLTIwMjAuaH RtbA\%253D.

[3] T. Irwani, "Kepuasan Kerja Guru Sekolah Dasar Dalam Kecamatan Johan Pahlawan Kabupaten Aceh Barat," Bina Gogik, vol. 4, no. 1, pp. 65-74, 2017.

[4] H. Hasanah, "Faktor-Faktor Yang Mempengaruhi Kepuasan Kerja," Manajer Pendidik., vol. 9, no. 1, 2015, doi: 10.31227/osf.io/wczd8.

[5] N. Ayu, A. Pitasari, and M. Surya Perdhana, "Kepuasan Kerja Karyawan : Studi Literatur," Diponegoro J. Manag., vol. 7, no. 4, pp. 1-11, 2018, [Online]. Available: http://ejournal-

s1.undip.ac.id/index.php/managemen t.

[6] N. M. Desa, M. H. Abu Hassan Asaari, A. A. Razak, and N. Diyanah Abd Jabar, "Communication and Job Satisfaction among Workers in the Department of Trade Union Affairs in the Northern State of Malaysia," Eur. Sci. J. ESJ, vol. 15, no. 28, 2019, doi: 10.19044/esj.2019.v15n28p1.

[7] A. D. Indrawati, "Pengaruh Kepuasan Kerja Terhadap Kinerja Karyawan Dan Kepuasan Pelanggan Pada Rumah Sakit Swasta Di Kota
Denpasar," J. Manajemen, Strateg. Bisnis dan Kewirausahaan, vol. 7, no. 2, pp. 135-142, 2013, doi: 10.24843/MATRIK:JMBK.

S. Murwani, N. Miyono, and Retnaningdyastuti, "PENGARUH PERAN KEPALA SEKOLAH DAN KEPUASAN KERJA TERHADAP KINERJA GURU SMP/MTS Di KECAMATAN SUSUKAN KABUPATEN SEMARANG," $J$. Manaj. Pendidik., vol. 9, no. 1, 2020.

[9] N. Mishra and R. P. Dimri, "Analysis of employee relationship management," J. Arts, Sci. Commer., vol. 2, no. 10, pp. 15-25, 2017.

[10] A. Tansel and Şa. GazîOğLu, "Management-employee relations, Firm size and job satisfaction," Int. J. Manpow., vol. 35, no. 8, pp. 12601275, 2014, doi: 10.1108/IJM-092014-0179.

[11] R. Pudjiastuti, "Pengaruh Komunikasi Dan Kepuasan Kerja Terhadap Produktivitas Guru Smp Negeri Di Sub-Rayon Bangsri Kabupaten Jepara," J. Pendidik. Sains Univ. Muhammadiyah Semarang, vol. 4, no. 2, pp. 59-70, 2016, doi: 10.26714/jps.4.2.2016.59-70.

[12] A. T. Akpinar, E. Torun, and O. Akpinar, "The Effect of Organizational Communication and Job Satisfaction on Organizational Commitment in Small Business," Interdiscip. J. Res. Bus., vol. 3, no. 04, pp. 27-32, 2013.

[13] R. Jelena, T. Edit, M. Maesa, I. Dragica, and N. Milan, "The impact of job and communication satisfaction on the financial performance of a midsize company," J. Contemp. Econ. Bus. Issues, vol. 5, no. 1, pp. 77-87, 2018.

[14] A. Ali and J. Haider, "Impact of internal organizational communications on employee job satisfaction- Case of some Pakistani," 
Glob. Adv. Res. J. Manag. Bus. Stud., vol. 1, no. x, pp. 38-44, 2012, [Online]. Available: garj.org/.../impact-of-internalorganizational-communications-onemployee-job-satisf...\%5Cn.

[15] K. G. W. Gunawan, I. Putrayasa, and I. W. Wendra, "Komunikasi Interpersonal Guru Dan Siswa Dalam Pembelajaran Teks Ulasan di Kelas VIII 10 SMP Negeri 2 Singaraja," $e$ Journal Prodi Pendidik. Bhs. dan Sastra Indones., vol. 7, no. 2, pp. 1689-1699, 2017.

[16] B. Mustika, "HUBUNGAN KOMUNIKASI ANTAR PRIBADI GURU DAN SISWA DENGAN MOTIVASI BELAJAR SISWA PADA MATA PELAJARAN ALQUR , AN HADIST DI MTS MIFTAHUL JANNAH PENDAHULUAN Dalam dunia pendidikan komunikasi memiliki peranan yang sangat penting khususnya komunikasi antarprib," AL-HIKMAH J. Pendidik. dan Pendidik. Agama Islam, vol. 1, no. 2, pp. 109-121, 2019.

[17] M. A. Rasyid and H. Tanjung, "Pengaruh Kompensasi, Lingkungan Kerja dan Motivasi Terhadap Kepuasan Kerja Guru pada SMA Swasta Perkumpulan Amal Bakti 4 Sampali Medan," Maneggio J. Ilm. Magister Manaj., vol. 3, no. 1, pp. 6074, 2020, doi: 10.30596/maneggio.v3i1.4698.

[18] F. M. Sari, "Pengaruh Kompetensi dan Lingkungan Kerja Terhadap Kepuasan Kerja dan Kinerja Guru di SD Negeri Kecamatan Gondang Mojokerto," DIE J. Ilmu Ekon. Manaj., vol. 9, no. 2, pp. 137-153, 2013.

[19] S. Iskandar and E. Juhana, "Terhadap Kepuasan Kerja Serta Implikasinya Pada Kinerja Guru Di Sdn Baros Mandiri 5 Kota," vol. 8, no. 2, pp. 8698, 2014.
[20] T. J. Kanana, "The Perceived Relationship Between Employee Relations Management Practices And Job Satisfaction At Swissport Kenya Limited," Eur. Manag. J., vol. 25, no. 7, pp. 12-35, 2016.

[21] H. Bulińska-Stangrecka and A. Bagieńska, "The role of employee relations in shaping job satisfaction as an element promoting positive mental health at work in the era of covid-19," Int. J. Environ. Res. Public Health, vol. 18 , no. 4 , pp. 1-19, 2021, doi: 10.3390/ijerph18041903.

[22] Ö. H. Kuzu and D. Özilhan, "The Effect of Employee Relationships and Knowledge Sharing on Employees' Performance: An Empirical Research on Service Industry," Procedia - Soc. Behav. Sci., vol. 109, pp. 1370-1374, 2014, doi: 10.1016/j.sbspro.2013.12.639.

[23] N. Soyomukti, Pengantar Ilmu Komunikasi, Cetakan II. Yogyakarta: Ar-Ruzz Media, 2012.

[24] Y. Rachmayuniawati, "Pengaruh Komunikasi Internal dan Koordinasi Terhadap Efektifitas Kerja pada Pegawai Rumah Sakit Prasetya Bunda Tasikmalaya," JIMFE (Jurnal Ilm. Manaj. Fak. Ekon., vol. 4, no. 1, pp. 67-80, 2018, [Online]. Available: http://awsassets.wwfnz.panda.org/do wnloads/earth_summit_2012_v3.pdf \%0Ahttp://hdl.handle.net/10239/131 \%0Ahttps://www.uam.es/gruposinv/ meva/publicaciones

jesus/capitulos_espanyol_jesus/2005 _motivacion para el aprendizaje Perspectiva alumnos.pdf\%0Ahttps://ww.

[25] S. Azeharie and N. Khotimah, "The Patterns of Interpersonal Communication between Teachers and Students in Children Daycare 'Melati' in Bengkulu,' J. Pekommas, vol. 18, no. 3, pp. 213-224, 2015.

[26] M. I. Hendri, "The mediation effect of job satisfaction and organizational 
commitment on the organizational learning effect of the employee performance," Int. J. Product. Perform. Manag., vol. 68, no. 7, pp. 1208-1234, 2019, doi: 10.1108/IJPPM-05-2018-0174.

[27] Suparman, D. wahyu A, and M. H. Arifin, "Pengaruh Motivasi dan Kepuasan Kerja Terhadap Kinerja Karyawan 9 Koperasi di Muara Teweh," J. Bisnis dan Pembangunan, ISSN 2541-187x, vol. 8, no. 1, pp. 5262, 2019.
[28] Mukhtar, Hapzi Ali and Rusmini, Kepuasan Kerja Guru. 2017.

[29] W. Kulachai, P. Narkwatchara, P. Siripool, and K. Vilailert, "Internal communication, employee participation, job satisfaction, and employee performance," $A d v$. Soc. Sci. Educ. Humanit. Res., vol. 186, pp. 124-128, 2018, doi: 10.2991/insyma-18.2018.31. 